\title{
JURISPRUDENCIA AMBIENTAL EN CASTILLA Y LEÓN (SEGUNDO SEMESTRE 2018)
}

\author{
IÑIGO SANZ RUBIALES \\ Catedrático de Derecho Administrativo \\ Universidad de Valladolid
}


Sumario: 1. Introducción. 2. Sobre la prescripción de infracciones en materia de aguas. 3. Planes de Ordenación del Territorio y validez de las autorizaciones ambientales. 4. Publicidad y validez de ordenanzas de residuos. 5. Caudales ecológicos y revisión de concesiones. 6. La obligación autonómica de elaborar Planes de mejora de la calidad del aire.

\section{INTRODUCCIÓN}

Son cada vez más numerosas las resoluciones judiciales que tienen por objeto conflictos ambientales; destacan cuantitativamente las relativas a las aguas (que no en vano es el primer recurso ambiental) y a las autorizaciones y licencias. En nuestra región, en este periodo debe destacarse la anulación, por la Sala de lo contencioso-administrativo del Tribunal Superior de Justicia, de la autorización ambiental integrada para la instalación de un centro de tratamiento de residuos industriales no peligrosos, como consecuencia de su falta de adecuación a un Plan de Ordenación del Territorio que protegía la zona como "corredor ecológico", y que, curiosamente, no había sido tenido en cuenta por el informe de la Diputación durante el trámite de la autorización en cuestión. Igualmente, debe destacarse la importancia del pronunciamiento de condena a la Administración para que elabore los Planes de Mejora de Calidad Ambiental de la Atmósfera en algunas zonas, como consecuencia de la superación de los valores de ozono en los últimos años.

\section{SOBRE LA PRESCRIPCIÓN DE INFRACCIONES EN MATERIA DE} AGUAS

La STSJ (Burgos) de 4 de junio de 2018 tiene un extraordinario interés jurídico porque pone de manifiesto los diversos tipos de infracciones - "instantáneas" 0 de estado- que, tipificadas por la Ley de Aguas, pueden cometerse por un mismo sujeto y aprovechando idéntica ocasión, pero que pueden también prescribir en momentos diferentes y dar lugar o no a las correspondientes sanciones o a otras medidas de reposición tipificadas en la misma Ley.

En este caso, a los recurrentes (que habían realizado actuaciones ilegales en el dominio público hidráulico y provocado daños en él) se les impusieron varias sanciones pecuniarias y se les intimó a la reposición de las cosas a su estado primitivo. Las infracciones cometidas estaban tipificadas en el artículo $116.3 \mathrm{~d}$ ) 
y e) del Texto Refundido de la Ley de Aguas de 20 de julio de 2001 (TRLA) y calificadas como leves en el art. 315 c ) y d) del Reglamento del Dominio Público Hidráulico de 11 de abril de 1986 (RDPH); se trataba en ambos casos de actuaciones sobre el dominio público hidráulico del cauce del río Cúa, así como de su zona de servidumbre y policía, sin concesión o autorización administrativa del Organismo de cuenca, mediante la instalación del camping "El Bierzo", en Villamartín de la Abadía (León). Eran dos las infracciones sancionadas: por una parte, la ocupación de los cauces sin la debida autorización -art. 116.3.e) TRLA y 315.d) RDPH- y por otra, la ejecución sin permiso de obras en los cauces públicos o en las zonas sujetas legalmente a algún tipo de limitación en su uso -artículos 116.3.d) TRLA y 315.c) RDPH.

La prescripción de sendas infracciones comienza (y termina, lógicamente) en momentos diferentes, hasta tal punto que la segunda, según afirma el Tribunal, había prescrito cuando se inició el procedimiento sancionador, por lo que solo podía perseguirse la primera. El motivo de esta distinción deriva de la naturaleza jurídica de las infracciones: la primera se configura como una infracción permanente (aunque la sentencia habla indistintamente de infracción permanente o continuada) mientras que la segunda es instantánea (aunque tampoco exactamente: los trabajos constructivos se realizan a lo largo de un cierto periodo de tiempo que, eso sí, tiene fin indudable). De esta forma, la infracción permanente no prescribe mientras no cese la actividad; la instantánea (aunque con efectos permanentes) se consuma, esto es, empieza a prescribir "cuando se terminan esas obras o trabajos, sin que el hecho de que sus efectos persistan"; "porque una vez terminada la obra cuya realización se sanciona y mientras no haya ninguna nueva actuación del autor no podrá decirse que éste ejecuta nada sin autorización, que es justo lo tipificado (STS 23 abril 2013 y sentencias del TSJCYL de 18 de octubre de 2012, 12 de diciembre de 2013 y 30 de septiembre de 2015)".

Pues bien, el camping al que se refiere la actividad infractora se construyó a principios de los años ochenta del siglo pasado y al menos desde septiembre de 2011 no hubo ningún cambio relevante o ampliación, por lo que cabe deducir fácilmente que la infracción consistente en la ejecución de obras había 
prescrito y que la única infracción subsistente era la de ocupación del cauce, que no ha prescrito porque se trata de una infracción permanente que se mantiene durante un espacio prolongado de tiempo por la persistencia de la voluntad del sujeto que, en cualquier momento, puede poner fin a la misma y que en tales casos " el cómputo para la prescripción comienza desde el cese de la actividad ilegal o desde que se elimina la situación ilícita " ( SSTS 20 noviembre 2007 y 20 septiembre 2012 ).

De acuerdo con ello, la sentencia anula una sanción y confirma otra. En todo caso, las medidas de reposición son independientes de este resultado, porque la prescripción de estas se rige por periodos mucho más largos y su imposición es compatible, tanto con la presencia como con la ausencia de sanciones. Resulta, en todo caso, sorprendente que la inactividad de la Administración hidráulica en la vigilancia de cauces públicos se prolongue durante decenios.

\section{PLANES DE ORDENACIÓN DEL TERRITORIO Y VALIDEZ DE LAS AUTORIZACIONES AMBIENTALES}

La STSJ (Valladolid) de 5 de julio de 2018 resuelve la impugnación de la Autorización Ambiental Integrada del Centro Integral de Tratamiento de Residuos Industriales No Peligrosos (CTRI), ubicado en una vaguada del páramo de Bárcena, a menos de un kilómetro del río Pisuerga, dentro del término municipal de San Martín de Valvení (Valladolid), otorgada el 7 de octubre de 2016, y de la Declaración de Impacto Ambiental (DIA) del Proyecto Regional del Centro Integral, fechada el día anterior (6 de octubre).

Por una parte, el órgano judicial confirma la inadmisibilidad del recurso contra la DIA, porque se trata de un acto de trámite de la resolución final que es, en este caso, un Proyecto Regional. Sin perjuicio de que dicha DIA se refiera al proyecto y no a la autorización ambiental y de que dicho proyecto no haya sido aprobado como tal (FD $2^{\circ}$ ), lo cierto es que la DIA no admite, en principio, impugnación autónoma, por tratarse (según la Ley) de un acto administrativo de trámite, cuya naturaleza es la de un informe preceptivo y no vinculante, tal y 
como establece el art. 4.3 d) Ley 21/2013, de 9 de diciembre, de Evaluación Ambiental.

Los motivos aducidos en la impugnación de la Autorización son variados; por una parte se afirma ( $j a$ estas alturas!) que infringe el régimen de distancias del RAMINP (Reglamento de Actividades Molestas, Insalubres, Nocivas y Peligrosas, aprobado por aprobado por Decreto 2414/1961, de 30 de noviembre, al ubicarse a una distancia de menos de 2.000 metros a contar del núcleo más próximo de población agrupada. Sin embargo, con buen criterio, la Sala confirma la inaplicabilidad de dicho Decreto en Castilla y León (según la Disposición derogatoria única de la Ley 11/2003) y desestima este motivo.

El recurso, igualmente, afirma la inadecuación de la ubicación del citado Centro de Transferencia de Residuos por las condiciones geotécnicas, geológicas e hidrogeológicas del terreno. Al igual que con el motivo anterior, la Sala rechaza esta argumentación, en este caso porque los demandantes no acreditan dicha inadecuación ni proponen prueba pericial alguna para confirmar su afirmación.

Finalmente, los recurrentes alegan igualmente que la citada Autorización Ambiental resulta contraria a lo dispuesto en el Plan Especial (PE) "Soto de Aguilarejo", aprobado definitivamente por Orden de 5 de junio de 1989 de la Consejería de Medio Ambiente y Ordenación del Territorio (BOCyL de 11 de agosto de 1989), y también a lo dispuesto en el Plan Regional de Ámbito Territorial del Valle del Duero, aprobado por Decreto 21/2010, de 27 de mayo, publicado en el BOCyL de 2 de junio de 2010. En relación con las exigencias de ordenación del territorio, la Sala recuerda que el art. 12 RD Legislativo 1/2016, por el que se aprueba el Texto Refundido de la Ley de Prevención y Control Integrado de la Contaminación, exige que se acredite la compatibilidad del proyecto con el planeamiento urbanístico. Pues bien, el informe urbanístico aportado a la tramitación de la Autorización, de la Diputación en este caso (porque el municipio carece de planeamiento propio) de 10 de marzo de 2015, afirma que el terreno en el que se ubicó dicha instalación tenía la calificación de no urbanizable común en las Normas Subsidiarias de la Provincia de Valladolid; de acuerdo con ello, la instalación para el tratamiento de residuos no peligrosos 
sería "autorizable" como uso excepcional, al amparo de lo dispuesto en el art. 59 del Reglamento de Urbanismo de Castilla y León, aprobado por Decreto 22/2004, de 29 de enero. Pero dicho informe no analiza las repercusiones que sobre el citado CITR pueden tener desde un punto de vista urbanístico el Plan Especial "Soto de Aguilarejo" y el Plan Regional del Valle del Duero.

De acuerdo con lo dicho, hay que valorar la compatibilidad del Proyecto en cuestión con los citados planes, aplicables al ámbito territorial en el que se ubica aquél. Pero debe distinguirse entre uno y otro Plan: el Plan Especial de Soto de Aguilarejo, aprobado definitivamente por la citada Orden de 5 de junio de 1989, no es eficaz al no haberse publicado su normativa urbanística, tal y como afirma el Tribunal. En efecto, la exigencia de la publicación de las normas de los planes urbanísticos como requisito para su vigencia fue establecida en el art. 70.2 Ley 7/1985, de Bases de Régimen Local (LBRL), por lo que en este caso, al no estar publicada dicha normativa, no son exigibles sus prescripciones.

Sin embargo, a diferencia del anterior, el Plan Regional de Ámbito Territorial del Valle del Duero, aprobado por Decreto 21/2010, de 27 de mayo, sí fue publicado en el BOCyL de 2 de junio de 2010. Se trata de un Plan de Ordenación del Territorio que incluye al citado municipio.

Como señala la sentencia, está acreditado por la documentación obrante que la ubicación del centro afecta a los "Corredores de enlace", a los que se refieren, dentro de los denominados "Corredores Ecológicos del Duero", los arts. 35 y ss. del Plan. El art. 36.3 dispone que "Los corredores ecológicos deben mantener la continuidad de su cubierta vegetal y su potencial como elementos conectores entre áreas de interés ecológico, ajustando su clasificación y potenciales usos a la garantía de esta continuidad". Y el párrafo siguiente: " El mantenimiento de los corredores debe incluir la conservación de la continuidad y del modelo de vegetación según los criterios ecológicos y técnicos adecuados favoreciendo la interconexión de los hábitats, la valoración de los ecotonos y la biodiversidad". 
Y dichos preceptos del Plan son vinculantes. Tienen carácter "básico" y no "pleno", lo que supone que vinculan solo en cuanto a sus fines (art. 6.3 b); en este caso, el fin de los preceptos citados es la propia conservación de la continuidad de los corredores ecológicos, fin que no se cumple en este caso como constata la sala, "toda vez que esa continuidad se interrumpe con el vial proyectado en el CITR". Esta constatación lleva a declarar la nulidad de la Autorización en cuestión.

Como confirma la sentencia, los Planes de Ordenación del Territorio, en cuanto normas jurídicas, tienen como misión ordenar imperativamente los usos del suelo y pueden ser vinculantes, tanto en sus prescripciones como en sus fines, en función del tipo de disposición de que se trate. Por eso las autorizaciones de instalaciones que infrinjan sus previsiones (de contenido o finalísticas) deben considerarse ilegales.

Por otra parte, no deja de ser curioso que ni siquiera el órgano provincial competente en esta materia sea consciente de la existencia de Planes de Ordenación del Territorio aplicables en ese ámbito territorial: la normativa "urbanística" en sentido amplio no se limita a los planes de alcance municipal, sino que trasciende a los de ordenación del territorio de ámbito supramunicipal que se imponen a aquellos.

\section{PUBLICIDAD Y VALIDEZ DE ORDENANZAS DE RESIDUOS}

La sentencia del TSJ (Valladolid) de 13 de julio de 2018 viene a confirmar la validez de una ordenanza municipal de residuos sólidos urbanos (del Ayuntamiento de San Pedro de Rozados, Salamanca), aprobada sin el informe de la empresa concesionaria, que se adjuntó extemporáneamente, y publicada sin el Anexo que determinaba la ubicación de los contenedores en la vía pública.

El Boletín Oficial de la provincia había publicado la Ordenanza aprobada, cuyo art. 13 se remitía a un Anexo, que a la vista del informe del concesionario, debía prever la ubicación de los contenedores: «En cualquiera de los 
supuestos anteriores, en el casco urbano, el Ayuntamiento determinará la ubicación de los distintos contenedores en la vía pública atendiendo a criterios de eficiencia, económicos, organizativos, de proximidad y accesibilidad para los usuarios y de salud y seguridad públicas y según el informe que al respecto se solicitará de la Empresa concesionaria del Servicio para la Mancomunidad y que se incorporará a la presente Ordenanza como Anexo.». Ahora bien, este Anexo II, al parecer por un error informático, no fue publicado en el mismo boletín oficial (de la provincia salmantina) sino en uno posterior.

El impugnante solicita la declaración de nulidad de la citada ordenanza por haber sido publicada sin el Anexo (que debía incorporarse a la Ordenanza, tal y como esta misma lo exigía) y por haber obtenido el informe de la concesionaria tardíamente.

El Tribunal recuerda que la publicación completa de la norma reglamentaria no es un requisito de validez, sino de eficacia, de acuerdo con lo que establece el art. 91 de la Constitución, el art. 2.1 del Código Civil, art. 70.2 LRBL y 131 de la Ley 40/2015, de Régimen Jurídico del Sector Público; este último recuerda: "Las normas con rango de ley, los reglamentos y disposiciones administrativas habrán de publicarse en el diario oficial correspondiente para que entren en vigor y produzcan efectos jurídicos (...)».

Por otra parte, se entiende como hecho probado que el informe en cuestión obraba en el expediente y no se incorporó a él de forma extemporánea. Este informe de la concesionaria puede identificarse con la documentación aportada por esta, gráfica y fotográfica, sobre la ubicación de contenedores, que se considera suficiente; en efecto, dichos documentos no iban acompañados de una explicación "escrita" relativa al contenido gráfico, que explicase los motivos de la ubicación establecida. Es cierto -dice la sentencia- que en el caso concreto no obra tal informe "escrito" en el expediente. Sin embargo, de forma complementaria, la concesionaria envió un email informando que los contenedores estaban "bien situados". Queda claro, por tanto, que la documentación existió, aunque fuese gráfica, y que la constatación de la 
ubicación de los contenedores fue aportada por la empresa concesionaria, a modo de informe "informal" (valga la redundancia).

El Tribunal, en definitiva, afirma la validez de la ordenanza, tanto por razón de su publicación en dos momentos (lo que únicamente afectó a la eficacia) como por razón de la demostrada existencia del trámite del informe en cuestión: de acuerdo con el principio de conservación y de economía procedimental, desestima el recurso porque las irregularidades formales alegadas no afectaron a la validez de la ordenanza.

\section{CAUDALES ECOLÓGICOS Y REVISIÓN DE CONCESIONES}

La STSJ (Valladolid) de 3 de julio se enfrenta a la impugnación de un acuerdo de inadmisión de la solicitud de revisión de una concesión hidráulica. La sociedad recurrente había solicitado la revisión de una antigua concesión para adaptarla al nuevo régimen de caudales ecológicos previsto en el RD 1/2016, de 8 de enero, y la correspondiente indemnización de 74.229,45 euros sobre la base de los informes periciales aportados.

Por una parte, resulta interesante comprobar que el nuevo régimen de caudales ecológicos (más favorable a los concesionarios que el anterior) ha sido parcialmente declarado nulo de pleno derecho. En efecto, la STS de 3 de octubre de 2018 anula el artículo 49 quinquies, apartado segundo, del RDPH, en la redacción del RD 638/2016, de 9 de diciembre, por el que se modifica dicho reglamento, y que se refería, en concreto, al control y seguimiento del régimen de caudales ecológicos (específicamente, a los supuestos de incumplimiento de dicho régimen) y que abría la posibilidad de que, cuando circunstancias especiales así lo aconsejen, el plan hidrológico de cuenca pueda fijar unas reglas menos exigentes.

Por otra parte, la sentencia estima parcialmente la pretensión en lo referido a la inadmisión de la solicitud. La resolución de inadmisión señalaba que la solicitud no cumplía ninguna de las exigencias previstas en el art. 65 TRLA para ello. Pero la inadmisión de una solicitud en vía administrativa, como enseña la 
sentencia, está regulada en el art. 88.5 de la Ley 39/2015, de Procedimiento Administrativo Común, y solo puede decidirse ante "solicitudes de reconocimiento de derechos no previstos en el ordenamiento jurídico o manifiestamente carentes de fundamento", supuestos ambos "que de modo incuestionable no se dan" en este caso. En efecto, "malamente cabe sostener que se pretende el reconocimiento de un derecho no previsto en el ordenamiento jurídico cuando se acciona con apoyo en el artículo 65 TRLA, precepto en el que de manera expresa se contempla la revisión de una concesión cuando lo exija su adecuación a los planes hidrológicos". En definitiva, la Administración confundió inadmisión con desestimación; la inadmisión exige que, de forma patente, falte la base legal de la pretensión; la desestimación solo puede darse cuando no es palmaria la falta de base legal de la solicitud.

La Administración hidráulica, así, ha incurrido además en una nulidad de pleno derecho al inadmitir la solicitud, porque ha prescindido total y absolutamente del procedimiento legalmente establecido, que aparece descrito y pautado con cierta pormenorización en los arts. 143 y ss. RDPH o en los arts. 159-160, en función de diversas circunstancias.

Ahora bien, una vez reconocido el derecho a la instancia, el Tribunal no se atreve, ni a determinar el alcance de la revisión de la concesión, ni a reconocer el derecho indemnizatorio, ni a concretar, en su caso, la suma a pagar. Y la razón es que no puede el Tribunal sustituir a la Administración en el ejercicio de sus potestades discrecionales. En efecto, el Organismo de cuenca disfruta de un cierto margen de discrecionalidad técnica, que le permite y obliga a determinar las condiciones de otorgamiento y de revisión de las concesiones (con la correspondiente motivación); además, el derecho a la indemnización contemplado en el artículo 65.3 TRLA se conecta con la revisión de la concesión y no con la simple solicitud de revisión. En consecuencia, el Tribunal Supremo anula la resolución de inadmisión e impone la retroacción de las actuaciones, para que la Confederación Hidrográfica del Duero tramite en forma la solicitud de revisión de concesiones presentada por la sociedad 
demandante. Cuál deba ser la solución de la instancia, a la luz de la reciente sentencia anulatoria del citado precepto del RDPH, es otra cuestión.

\section{LA OBLIGACIÓN AUTONÓMICA DE ELABORAR PLANES DE MEJORA DE LA CALIDAD DEL AIRE}

La STSJ (Valladolid) de 19 de octubre de 2018 condena a la Administración autonómica a elaborar y aprobar los preceptivos Planes de Mejora de la Calidad del Aire para las siguientes zonas: Salamanca, Duero Norte, Duero Sur, Montaña Sur, Valle del Tiétar y Alberche, Sur y Este de Castilla y León.

Se trata, como puede comprobarse, de una condena de "hacer", del cumplimiento de una obligación de facere que la Junta había eludido en espera de la correspondiente actuación estatal.

La vía procedimental elegida por los recurrentes suscitó diversas dudas, porque, si bien se inició con una solicitud (fechada el 22 de enero de 2016) de adopción de dichos Planes de Mejora de la Calidad del Aire, como pretensión contra la inactividad administrativa, lo cierto es que, tras la desestimación de dicha solicitud (mediante la remisión de un informe del Servicio de Prevención Ambiental y Cambio Climático de la Consejería que consideraba más adecuada la adopción de un Plan Nacional de ozono), se impugnó el acto desestimatorio en vía contenciosa. En todo caso, el Tribunal, de acuerdo con el principio pro actione, entendió que no existía divergencia en el objeto del proceso, porque en todo caso se estaba refiriendo a la falta de respuesta por parte de la Administración frente a la solicitud inicial.

La asociación recurrente avaló su pretensión en los datos de incumplimientos de los valores objetivos relativos al ozono troposférico en determinadas zonas desde el año 2012; y trajo a colación las previsiones del art. 16 de la Ley 34/2007, de calidad del aire atmosférico, que obliga a las Comunidades Autónomas a elaborar estos Planes: "Las Comunidades Autónomas... adoptarán... los Planes... a) De mejora de la calidad del aire para alcanzar los objetivos de calidad del aire en los plazos fijados, en las zonas en las que los 
niveles de uno o más contaminantes regulados superen dichos objetivos" (en el mismo sentido, también lo obliga el art. 24 RD 102/2011, de 28 de enero, relativo a la mejora de la calidad del aire).

Pues bien, este último precepto reglamentario $-y$ así lo señala la sentenciaestablece en el apartado $5^{\circ}$ que: "Independientemente de lo anterior (de la elaboración de los planes por las Comunidades Autónomas), y de acuerdo a sus competencias, la Administración General del Estado elaborará Planes nacionales de mejora...". Por lo tanto, los Planes autonómicos y estatal no están mutuamente condicionados en lo que se refiere a su elaboración, por lo que la obligación del Estado de ejercer su competencia no puede ser una excusa para que no lo haga la Comunidad Autónoma, obligada por la Ley estatal básica.

De acuerdo con todo lo anterior, habida cuenta del cumplimiento del supuesto de hecho necesario para la elaboración y aprobación de los citados Planes, la Sala condena a la Administración autonómica a elaborarlos. Lógicamente, no impone un contenido específico (ni un plazo determinado, a pesar de que se solicitó por la asociación recurrente) que depende de las previsiones legales y de la discrecionalidad administrativa. 